\title{
INTERSECCIONALIDADE E DIREITOS HUMANOS: UMA ANÁLISE DA SENTENÇA DO CASO DOS EMPREGADOS DA FÁBRICA DE FOGOS DE ARTIFÍCIOS EM SANTO ANTÔNIO DE JESUS (BA)
}

\author{
Arianne Albuquerque de Lima Oliveira ${ }^{1} *$ \\ Edna Raquel Rodrigues Santos Hogemann**
}

\section{RESUMO}

Focaliza a interseccionalidade como um dos parâmetros possíveis do constitucionalismo contemporâneo. Examina a interconexão das noções fundamentais de não discriminação, raça, gênero, classe e mercado de trabalho no desenho da noção de interseccionalidade a partir da análise da sentença proferida pela Corte Interamericana de Direitos Humanos, no caso da explosão da fábrica de fogos de artifícios em Santo Antônio de Jesus (BA) buscando inspiração no pensamento de Kimberlé Crenshaw. Trata-se de exploratória, qualitativa, com recursos bibliográficos e método dialético, evidenciando a relevância do papel da Corte e a indispensabilidade de uma leitura e aplicabilidade interseccional dos direitos humanos.

PALAVRAS-CHAVE: Interseccionalidade; aplicabilidade; Corte Interamericana de Direitos Humanos; Direitos Humanos; Gênero.

\section{INTERSECTIONALITY AND HUMAN RIGHTS: AN ANALYSIS OF THE SENTENCE IN THE CASE OF FIREWORKS FACTORY EMPLOYEES IN SANTO ANTÔNIO DE JESUS (BA)}

\begin{abstract}
It focuses on intersectionality as one of possible parameters of contemporary constitutionalism. It examines the interconnection of fundamental notions of nondiscrimination, race, gender, class and labour market in the design of notion of intersectionality based on analysis of the judgment handed down by Inter-American Court of Human Rights in case of explosion of the fireworks factory in Santo Antônio de Jesus (BA), drawing inspiration from thought of Kimberlé Crenshaw. This is an exploratory, qualitative study, with bibliographical resources and dialectical method, highlighting the relevance of the Court's role and indispensability of an intersectional reading and applicability of human rights.
\end{abstract}

KEY WORDS: Intersectionality; applicability; Inter-American Court of Human Rights; Human Rights; Gender.

\footnotetext{
1 * Mestranda em Direito pela Universidade Federal do Estado do Rio de Janeiro (UNIRIO), membra do Grupo Direito Humanos e Transformação Social (CNPq) e da Clínica de Enfrentamento ao Trabalho Escravo da Universidade Federal de Uberlândia. Graduada em Direito pela Universidade Veiga de Almeida (UVA). Advogada. E-mail: ariannealbuquerque@edu.unirio.br.

** Pós-doutora em Direito (UNESA), doutora e mestre em Direito (UGF). Especialista em Bioética pela Cátedra em Bioética da UNESCO. Especialista em Direitos Humanos pela Universidade de Coimbra, Portugal. Professora permanente do Programa de Pós-Graduação em Direito da Universidade Federal do Estado do Rio de Janeiro. Decana do Centro de Ciências Jurídicas, Políticas e de Administração, da Universidade Federal do Estado do Rio de Janeiro. Coordenadora do Grupo Direito Humanos e Transformação Social (CNPq). E-mail: edna.r.hogemann@unirio.br.
} 


\section{INTRODUÇÃO}

No ano de 2020, a Corte Interamericana de Direitos Humanos (Corte IDH) proferiu uma sentença condenando internacionalmente o Estado brasileiro por violar alguns dos direitos previstos na Convenção Americana sobre Direitos Humanos (1969), no caso que ficou conhecido como "os Empregados da Fábrica de Fogos de Artifício de Santo Antônio de Jesus e seus familiares vs. Brasil”, originado a partir de um trágico acidente ocorrido no ano de 1998, em uma fábrica de fogos, localizada no Recôncavo Baiano. Ao longo da sentença, a Corte realizou considerações relevantes acerca da proibição da discriminação, trazendo uma análise e argumentos aparentemente de cunho interseccional.

Inequívoca a importância política das decisões da Corte IDH e seus reflexos perante a Organização dos Estados Americanos caso o Estado não venha cumpri-la, pois ao reconhecer a jurisdição da Corte Interamericana configurada está um importante e eficaz espaço complementar de garantia aos direitos humanos sempre que as instituições nacionais se apresentem omissas ou falhas.

De igual modo, a realidade objetiva está a apontar que as opressões de classe interagem com outras categorias estruturais, como gênero, raça, operando processos de exclusão próprios que se constituem como barreiras ao acesso a direitos, constituindo-se a interseccionalidade um instrumento com especial potencialidade para que seja possível alcançar uma melhor compreensão desses processos, enfrentá-los e estabelecer ferramentas e estratégias de superação na busca pela eficácia dos Direitos Humanos. Razão pela qual o presente estudo se propõe a responder a seguinte questão: a sentença prolatada pela Corte IDH no caso dos Empregados da Fábrica de Fogos de Artifício de Santo Antônio de Jesus (BA) foi interseccional?

A partir da utilização do conceito de interseccionalidade, apurado por Crenshaw, em seu artigo intitulado Background Paper for the Expert Meeting on the Gender-Related Aspects of Race Discrimination (1989), as autoras do presente ensaio pretendem promover uma análise reflexiva sobre o entendimento trazido pela Corte no caso em questão. Ressaltase que a pesquisa se limita aos recortes de raça, gênero, classe, mercado de trabalho, se atentando para as vulnerabilidades que atingiram as trabalhadoras vítimas da tragédia e ao direito a não discriminação.

A fim de atingir o objetivo proposto, primeiramente será necessário abordar o conceito e a finalidade da interseccionalidade, com base nos fundamentos da autora Kimberlé 
Crenshaw. Assim, as autoras pretendem lançar luzes sobre a complexidade do pensamento crenshawniano e a sua contribuição, não somente por seu potencial analítico para a concretização do acesso das mulheres aos Direitos Humanos, como também para a identificação de alguns elementos essenciais para a ampliação e inclusão dessa temática na agenda dos Direitos Humanos.

Após, será realizada uma exposição sobre o caso da explosão da fábrica de fogos de Santo Antônio de Jesus (BA), seguido de uma análise do plano normativo brasileiro sobre o direito à não discriminação; por fim, será devidamente apresentada e analisada a sentença prolatada no caso retromencionado.

\section{INTERSECCIONALIDADE: "O CRUZAMENTO DAS AVENIDAS IDENTITÁRIAS"}

Conceber a interseccionalidade é partir do pressuposto de um indivíduo edificado sob múltiplos sentidos, ou seja, que o sujeito deve ser considerado em suas múltiplas dimensões que se entrecruzam, qual seja: raça, gênero, religião, classe etc. Crenshaw (2002) teve esse entendimento quando idealizou o termo interseccionalidade para demonstrar a interrelação de dependência das relações de poder de raça, sexo e classe, as quais as mulheres negras estão submetidas e por isso profundamente marginalizadas ${ }^{2}$. Noção que Akotirene (2020) considera possuir como objetivo instrumentalizar de forma teórico-metodológica a indissociabilidade estrutural do racismo, capitalismo e cisheteropatriarcado.

Nas palavras de Crenshaw:
A interseccionalidade é uma conceituação do problema que busca capturar as consequências estruturais e dinâmicas da interação entre dois ou mais eixos da subordinação. Ela trata especificamente da forma pela qual o racismo, o patriarcalismo, a opressão de classe e outros sistemas discriminatórios criam desigualdades básicas que estruturam as posições relativas de mulheres, raças, etnias, classes e outras. Além disso, a interseccionalidade trata da forma como ações e políticas específicas geram opressões que fluem ao longo de tais eixos, constituindo aspectos dinâmicos ou ativos do desempoderamento. (2002, p. 177)

\footnotetext{
${ }^{2}$ Aqui, cumpre resgatar o importante papel de Lélia Gonzalez - intelectual, ativista, antropóloga brasileira, dissertou em suas participações em seminários, congressos internacionais, e ainda na condição de professora da Pontifícia Universidade Católica do Rio de Janeiro (PUC-RIO). Lélia se destacou nas décadas de 1970 a 1990 por suas contribuições na construção do feminismo negro brasileiro, e por sua crítica radical ao capitalismo, na construção das agendas do movimento negro brasileiro. Para Lélia, o capitalismo estruturava muitas das opressões sexistas e racistas. Também foi uma das primeiras pensadoras negras brasileiras a abordar as discussões de gênero, raça, classe, e outras intersecções de forma não segmentada. Ela compreendia que essas bandeiras atravessavam corpos de forma relacional, e a admissão das pluralidades de corpos negros implicaria na valorização da cultura afrobrasileira, bem como das religiões de matriz africana. (Disponível em: https://repositorio.ufsc.br/handle/123456789/217008?show=full. Acesso em 03 set 2021)
} 
Ao longo da construção do conceito interseccional, Crenshaw (2002) demonstrou como uma análise somente a partir do gênero ou da raça pode ser prejudicial para os grupos vulneráveis. A autora expôs tal ideia a partir de dois conceitos, sendo eles a superinclusão e a subinclusão. Na superinclusão um problema ou uma condição específica é normalmente atribuído como um "problema de mulheres". Essa superinclusão acontece quando um problema é interseccional, no entanto, ele acaba sendo absorvido pela perspectiva do gênero, ignorando fatores como o racismo ou outras formas de discriminação que incidiram. Para exemplificar, tem-se a questão das mulheres traficadas. A autora considera que há uma correlação entre marginalização racial e social; todavia, o tráfico é absorvido pela estrutura do gênero, sem que haja um debate sobre raça ou outras subordinações que estão envolvidas nesse problema.

Já a subinclusão se mostra como questão coexistente à superinclusão. Ela ocorre quando algum grupo de mulheres enfrenta uma problemática em razão de seu gênero, no entanto, essa problemática não é reconhecida como um problema de gênero, uma vez que não está dentro da realidade e vivência das mulheres que pertencem ao grupo hegemônico (CRENSHAW, 2002). Em suma, "nas abordagens subinclusivas da discriminação, a diferença torna invisível um conjunto de problemas, enquanto que, em abordagens superinclusivas, a própria diferença é invisível” (CRENSHAW, 2002, p. 176).

Para realizar uma análise interseccional, primeiramente, é necessário compreender que a interseccionalidade "sugere que, na verdade, nem sempre lidamos com grupos distintos de pessoas e sim com grupos sobrepostos" (CRENSHAW, 2012, p. 10). Isto é, a sobreposição mostra como as mulheres negras podem sofrer diversas discriminações ao mesmo tempo, vejamos o exemplo:

(...) ao sobrepormos o grupo das mulheres com o das pessoas negras, o das pessoas pobres e também o das mulheres que sofrem discriminação por conta da sua idade ou por serem portadoras de alguma deficiência, vemos que as que se encontram no centro - e acredito que isso não ocorre por acaso - são as mulheres de pele mais escura e também as que tendem a ser as mais excluídas das práticas tradicionais de direitos civis e humanos (CRENSHAW, 2012, p. 10).

A analogia mais reconhecida da autora é a utilização de ruas/avenidas para demonstrar a interseccionalidade. As ruas/avenidas em diversos sentidos- norte, sul, leste e oeste- e que se cruzam umas com as outras, consistem na estrutura da discriminação- raça, gênero, entre outras- já o tráfego, que são os carros que passam nas intersecções entre essas 
ruas, representa as políticas ou leis que excluem um grupo. Logo, ao posicionar um indivíduo onde essas ruas/avenidas se cruzam, ele é atingido simultaneamente por diversos tráfegos e isso configura a coalizão das avenidas identitárias:

\begin{abstract}
(...) o racismo, por exemplo, é distinto do patriarcalismo, que por sua vez é diferente da opressão de classe. Na verdade, tais sistemas, frequentemente, se sobrepõem e se cruzam, criando intersecções complexas nas quais dois, três ou quatro eixos se entrecruzam. As mulheres racializadas frequentemente estão posicionadas em um espaço onde o racismo ou a xenofobia, a classe e o gênero se encontram. Por consequência, estão sujeitas a serem atingidas pelo intenso fluxo de tráfego em todas essas vias (CRENSHAW, 2002, p.177).
\end{abstract}

Outro ponto relevante e, seguindo a linha de pensamento das autoras Cho, Crenshaw e McCall (2013), não é a utilização do termo interseccionalidade que faz com que uma análise seja interseccional. Para essa análise é indispensável adotar uma maneira interseccional de pensar sobre o problema, ou seja, percebendo que as discriminações que atingem as mulheres negras não são apenas de gênero ou de raça ou classe, mas sim a associação dessas. $\mathrm{O}$ propósito precisa ser "o que a interseccionalidade faz ao invés do que a interseccionalidade é" (CHO, CRENSHAW e MCCALL, 2013, p. 795).

Assim, a interseccionalidade surge como ponte para que as questões de raça e gênero sejam trabalhadas conjuntamente dentro das perspectivas dos direitos humanos (CRENSHAW, 2012), a fim de que as mulheres negras, que se encontram na base da pirâmide social e são atingidas pelo cruzamento de diversas avenidas identitárias, não sejam excluídas. A análise interseccional deve ter como foco a compreensão da discriminação interseccional, que será o apoio para buscar a equidade e para propor mudanças que alcancem tanto o plano formal quanto o prático das leis e das políticas públicas. De tal modo que permite uma melhor compreensão das desigualdades e a aposição de distintas formas de opressão e discriminação encontradas no seio social.

Um olhar interseccional para a sentença do caso dos empregados da Fábrica De Fogos de Artifícios, em Santo Antônio de Jesus (BA) pode ser considerado enquanto uma contribuição instrumental analítica importante para pensar-se sobre as relações sociais de raça, sexo e classe, e os desafios que estão postos para a adoção de políticas públicas eficazes.

\title{
3. PANORAMA SOCIOESPACIAL DO RECÔNCAVO BAIANO E O CASO DA EXPLOSÃO DA FÁBRICA DE FOGOS DE ARTIFÍCIOS EM SANTO ANTÔNIO DE JESUS
}


Antes de adentrar-se na análise propriamente dita da sentença exaradas pela Corte, necessário se faz traçar um perfil geopolítico, social e laboral do cenário específico em que se desenrolou a tragédia que vitimou dezenas de trabalhadores, em sua maioria mulheres e meninas.

O Município de Santo Antônio de Jesus, local em que ocorreu a explosão, situa-se no Recôncavo Baiano, próximo à Salvador, capital do estado da Bahia (BA).

Oportuno sublinhar que a história do estado brasileiro da Bahia é marcada fortemente pelo tráfico de escravos nos períodos colonial e do Império. De acordo com Gomes (2019), Salvador foi o segundo maior porto negreiro da história, sendo responsável pelo tráfico de cerca de 1,3 milhões de africanos ${ }^{3}$.

Como consequência dessa dinâmica, grande parte da atual população do estado baiano é descendente de escravos africanos, sofrendo até hoje com desigualdades socioeconômicas, uma vez que os escravos libertos, a partir dos efeitos do nosso modelo de abolição da escravidão - Lei Áurea (1888), tiveram que continuar se submetendo a condições socioeconômicas degradantes, em razão da precária integração da população negra ao contexto da cidadania brasileira (desde a abolição até os nossos dias), causando profundas desigualdades sociais, econômicas, educacionais e culturais que atingem de forma contundente um amplo contingente de negros e mestiços.

Especificamente em Santo Antônio de Jesus essa é a situação. Sua população é de maioria afrodescendente. Conforme o Atlas do Desenvolvimento Humano no Brasil (2017), $76,45 \%$ são negros e 22,38\% são brancos. Além disso, a oferta de emprego no município é escassa, o que resulta em excesso de mão-de-obra, aumento do trabalho informal e precarizado, não havendo políticas públicas para a inserção dos trabalhadores no mercado de trabalho (TOMASONI, 2015).

Apesar desse cenário, o município é reconhecido como um dos grandes produtores de fogos de artifícios no Nordeste, sendo uma das bases para o Brasil manter sua posição de segundo maior país fabricante de fogos de artifícios, ficando apenas atrás da China (TARDÁGUILA, 2015).

\footnotetext{
${ }^{3} \mathrm{O}$ Brasil recebeu perto de quatro milhões de escravos, durante os mais de três séculos de duração do regime escravagista. Pelo Cais do Valongo, na região portuária da cidade do Rio de Janeiro, passou cerca de um milhão de africanos escravizados em cerca de 40 anos, o que o tornou o maior porto receptor de escravos do mundo. (Cais do Valongo. Disponível em: http://portal.iphan.gov.br/pagina/detalhes/1605/)
} 
Conforme destacado na sentença proferida pela Corte IDH (2020), a produção dos fogos, em Santo Antônio de Jesus, normalmente ocorre em tendas clandestinas, situadas nas regiões periféricas da cidade, sendo que as condições de segurança e salubridade não são observadas, o que traz consequências nocivas para a vida dos trabalhadores.

Nessa atividade é perceptível a divisão sexual do trabalho. A produção do traque, conhecido também como estalo de salão, "estalinho" e/ou "bombinha", a depender da região, é uma função que cabe ao gênero feminino. De acordo com uma trabalhadora, os homens não enrolam traque por terem vergonha, pois só as mulheres sabem fazer isso. A mão-de-obra masculina é voltada para a produção da "massa", que é utilizada para a confecção do estalo. A manipulação dessa massa consiste em atividade de grande risco, uma vez que exige a exatidão no uso dos elementos utilizados, como álcool, ácido nítrico, entre outros (TOMASONI, 2015). O nível de escolaridade das trabalhadoras em geral é ensino fundamental completo, ademais, muitas delas já trabalham nessa função desde crianças, tendo aprendido a atividade com familiares ou vizinhos (CORTE IDH, 2020).

O caso dos "Empregados da Fábrica de Fogos de Artifícios de Santo Antônio de Jesus e seus familiares vs Brasil", levado até a Corte Interamericana de Direitos Humanos, trata da explosão de uma fábrica de fogos, ocorrida no dia 11 de dezembro de 1998, no município de Santo Antônio de Jesus (BA). A fábrica era conhecida popularmente como “fábrica de Vardo dos fogos", pertencente a um empresário reconhecido da região, Osvaldo Prazeres Bastos.

Estima-se que estiveram presentes aproximadamente 70 pessoas no dia da tragédia. Tal fatalidade causou a morte de 60 trabalhadores, sendo 40 mulheres, em sua maioria afrodescendentes, havendo quatro grávidas, além disso, 19 meninas e 1 menino, apenas seis pessoas sobreviveram (CORTE IDH, 2020). Quando ocorreu a explosão, conforme Relatório de Mérito da Comissão Interamericana de Direitos Humanos- CIDH (2018), a fábrica possuía autorização do Ministério do Exército, do Município e o Certificado de Registro emitido no ano de 1995, com vigência até 31 de dezembro de 1998. Entretanto, não havia fiscalização, situação confirmada pelo próprio Estado brasileiro.

As condições de trabalho na fábrica eram demasiadamente degradantes. De acordo com depoimentos prestados em audiência pública perante a Corte IDH (2020), o local de trabalho era constituído por um conjunto de tendas em um pasto, havendo algumas mesas compartilhadas. Os materiais explosivos ficavam no mesmo ambiente que as trabalhadoras. 
Além disso, estas não tinham descanso, nem sequer alimentação ou banheiro. Os contratos eram informais e os salários baixos. Ressalta-se que as trabalhadoras necessitavam produzir mil traques para receberem a quantia de $\mathrm{R} \$ 0,50$ (cinquenta centavos), configurando claramente uma jornada exaustiva e um aviltamento da dignidade (CORTE IDH, 2020).

As trabalhadoras precisavam lidar com a situação de não terem opção de trabalho na região, bem como com o preconceito em razão da sua cor e da condição social. O depoimento cedido por uma das sobreviventes, Leila Cerqueira dos Santos, expõe profundamente a realidade:

\begin{abstract}
(...) ou trabalhávamos na fábrica ou em casas de famílias, mas muitas famílias não nos empregavam porque pensavam que éramos de um bairro pobre e que poderíamos furtar ou cometer furtos, e então nos discriminavam, não nos aceitavam e nos diziam venham amanhã, e sempre acontecia essa história (CORTE IDH, 2020, pag. 23).
\end{abstract}

Após a tragédia, foram instaurados processos internos, tanto administrativos, quanto judiciais nas áreas cível, penal e trabalhista, para averiguar o caso e indenizar as vítimas e os familiares. Todavia, diante da ausência de celeridade e eficiência para a reparação, o caso foi denunciado à CIDH, em 2001 e, posteriormente, foi levado até à Corte IDH, em 2018, por meio do Relatório de Mérito nº 25/18.

Importa destacar que no ano de 1998, cerca de 2.000 mulheres trabalhavam na fabricação de fogos de artifícios na região de Santo Antônio de Jesus (BA) e, inclusive, inseriam seus filhos na produção, tanto para aumentar a produção, quanto por não terem com quem deixá-los. Além disso, a explosão ocorrida em 1998 não foi a primeira. Localizou-se um processo penal, de abril de 1996, que condenava Osvaldo Prazeres Bastos em razão de uma explosão ocorrida nas dependências de suas atividades pirotécnicas (CORTE IDH, 2020).

Mais um agravante para o caso em questão era o fato de não haver equipamentos de proteção individual às trabalhadoras, muito menos capacitação, tornando o ambiente de trabalho ainda mais nocivo à vida (CORTE IDH, 2020).

Faz-se necessário citar que os acidentes ocorridos em fábricas de fogos de artifícios não se restringem somente ao município de Santo Antônio de Jesus (BA), ademais, tais acidentes são constantes. A ausência de segurança nesta atividade ceifa a vida de diversos trabalhadores. Como exemplo, cabe mencionar também a cidade de Santo Antônio do Monte, localizada no estado de Minas Gerais (MG). A região possui cerca de 72 fábricas e já ocorreram duas explosões em um mesmo dia numa empresa de fogos. Foram registrados no 
município, entre os anos de 2012 e 2015, o total de oito acidentes, havendo 14 mortes (TARDÁGUILA, 2015).

Ante o exposto, conforme pode-se constatar, as histórias se repetem, alterando apenas os locais e os personagens. A situação da pobreza, da falta de opção para trabalho conduzem os trabalhadores a se submeterem a situações evidentemente degradantes, tendo um peso maior ainda para as trabalhadoras, que muitas das vezes precisam introduzir seus filhos nessa atividade tão perigosa, bem como lidar com a separação da atividade por gênero e o preconceito diante da sua cor e sua classe.

Nesse ensejo, apesar do caso da explosão da fábrica de fogos de Santo Antônio de Jesus (BA) expor a realidade dura do trabalho em atividade pirotécnica, desde acidentes, jornadas exaustivas, trabalho infantil, a análise se pautará nas trabalhadoras vítimas dessa tragédia ocorrida no dia 11 de dezembro de 1998, observando como a raça, o gênero e a classe interferiram profundamente na vulnerabilidade destas no mercado de trabalho.

\section{O DIREITO A NÃO DISCRIMINAÇÃO E A VULNERABILIDADE DA MULHER AFRODESCENDENTE NO MERCADO DE TRABALHO BRASILEIRO}

O Brasil ratificou diversos instrumentos internacionais que vedam a discriminação. Tendo em vista que o trabalho não pretende ser exaustivo na abordagem, selecionou-se os tratados e as convenções relevantes para o tema. Inicialmente, há a Convenção Americana de Direitos Humanos, que em seus artigos 1.1 e 24 protege o direito à igualdade, além disso, a Convenção Internacional sobre a Eliminação de Todas as Formas de Discriminação Racial estabelece que a discriminação racial ocorre quando há qualquer distinção, exclusão, restrição ou preferência que seja fundamentada na cor, raça, descendência, origem nacional ou étnica, que tenha como finalidade impedir com que o indivíduo goze de seus direitos (BRASIL, 1969).

Outra convenção de alta relevância é a Convenção sobre a Eliminação de Todas as Formas de Discriminação contra a Mulher, que entende que a discriminação contra a mulher se configurará quando houver distinção, exclusão ou restrição fundamentada no sexo, obstaculizando o acesso desta aos seus direitos fundamentais (BRASIL, 2002).

No âmbito trabalhista, a Convenção $\mathrm{n}^{\mathrm{o}} 111$, da Organização Internacional do Trabalho (OIT), sobre Discriminação em Matéria de Emprego e Ocupação dispõe: 
Para os fins da presente convenção o termo 'discriminação' compreende: a) toda distinção, exclusão ou preferência fundada na raça, cor, sexo, religião, opinião política, ascendência nacional ou origem social, que tenha por efeito destruir ou alterar a igualdade de oportunidade ou de tratamento em matéria de emprego ou profissão" (BRASIL, 2019).

Importa salientar que o direito a não discriminação está intimamente interligado ao princípio da igualdade, que é um dos princípios basilares da Constituição Federal Brasileira de 1988 (CF/88). O art. 5º caput, da CF/88, versa sobre a igualdade formal, isto é, a lei é igual para todos, os direitos fundamentais são direitos de todos, sem qualquer distinção, seja de cor, sexo ou gênero.

Essa igualdade formal, apesar de importante, traz em seu bojo contradições, visto que homogeneíza os seres humanos, como se todos tivessem as mesmas experiências, histórias e vulnerabilidades. Seguindo a linha de entendimento de Kapur (2006), o direito se mostra muitas das vezes como um discurso complexo e contraditório, em razão de que a lei pode acabar se tornando mais eficaz e protetiva para aqueles que possuem menos vulnerabilidade e mais recursos.

Especificamente em relação à mulher, a lei, frequentemente, traz a figura de uma mulher universalista sendo ela branca, heterossexual, ocidental, classe média, ignorando que há questões de raça, religião, orientação sexual (KAPUR, 2006) e entre outras variáveis que as tornam diferentes entre si e as colocam em um contexto de vulnerabilidade desigual.

O tratamento restrito somente a uma igualdade puramente formal pode trazer prejuízos. Em resposta a esta situação, atualmente tem-se aplicado o entendimento da igualdade substancial ou material, que reconhece que os indivíduos são plurais, que há a incidência da diversidade, posto isto, tratar todos de forma idêntica pode marginalizar mais intensamente quem se encontra em um contexto de maior vulnerabilidade.

Em outras palavras, o Estado precisa observar tanto a igualdade de jure quanto a igualdade de facto, devendo assumir uma postura a evitar a violação do direito a não discriminação. Nesse sentido, expôs o Comitê de Direitos Econômicos, Sociais e Culturais da Organização Geral das Nações Unidas (2005):

7. O gozo dos direitos humanos com base na igualdade entre homens e mulheres deve ser compreendido de forma abrangente. As garantias de não discriminação e de igualdade nos tratados internacionais de direitos humanos exigem igualdade de fato e de jure. Igualdade de jure (ou formal) e igualdade de facto (ou substantiva) são conceitos diferentes, mas interconectados. A igualdade formal assume que a igualdade é alcançada se uma lei ou política trata homens e mulheres de maneira 
neutra. A igualdade substantiva está preocupada, além disso, com os efeitos das leis, políticas e práticas e com a garantia de que elas não mantêm, mas que aliviam, a desvantagem inerente de que experiência de grupos particulares (tradução nossa).

No sentido de corroborar que a vulnerabilidade em relação ao gênero feminino não atinge todas as mulheres igualmente, cabe realizar um breve exame, não exaustivo, do mercado de trabalho brasileiro. Indo de um plano mais geral, baseado em um olhar somente de gênero e trabalho, é possível perceber que as mulheres se encontram em situação grave de discriminação. Conforme estudo realizado pelo Instituto de Pesquisa Econômica AplicadaIPEA (2017), as mulheres realizam uma jornada de trabalho em média, por semana, de 7,5 horas a mais do que os homens, e mais de $90 \%$ destas informaram que executam trabalhos domésticos, proporção que não se alterou ao longo do tempo.

Tais dados expõem claramente a incidência da divisão sexual do trabalho, além dessa divisão, tem-se a questão do gender pay gap - a diferença salarial entre homens e mulheres as mulheres ainda ganham, em média, 20,5\% menos do que os homens (ESTATÍSTICAS SOCIAIS, 2019). Nessa linha sobre as diferenças salariais, argumenta a autora Fredman (2010):

(...) as mulheres muitas vezes estão em uma posição em que não têm opção a não ser aceitar a precariedade e condições de trabalho e remuneração exploradoras. Sem valor econômico atribuído a atividades não remuneradas, a contribuição das mulheres permanece invisível. (p. 5, tradução nossa)

Aprofundando essa análise a partir de um recorte de gênero, raça e trabalho, percebese que, ainda que as discriminações entre os gêneros no mercado de trabalho atinjam as mulheres em geral, tal situação pode ser pior para a mulher negra. Segundo Soares (2000), a desigualdade salarial pode ser dividida entre quatro grupos, a saber, de homens negros, homens brancos, mulheres negras e mulheres brancas. Além disso, há três fatores que incidem nessa desigualdade, que são a formação, a inserção e a discriminação salarial. A primeira consiste na qualificação profissional, já a segunda é a inserção do indivíduo no mercado de trabalho e a terceira é a diferença salarial.

Os homens negros, se comparados com os homens brancos, estão em desvantagem em razão da formação e inserção, visto que os primeiros têm uma escolaridade deficiente e as posições de trabalho são normalmente de menor prestígio. Em relação às mulheres, para as brancas incidem a discriminação e inserção, dado que ainda que apresentem um nível maior de escolaridade, ocupam cargos intermediários, ou mesmo que ocupem cargos iguais aos dos 
homens, ganham menos. Já as mulheres negras, diferentemente dos outros grupos, suportam a incidência dos três fatores: formação, inserção e discriminação (SOARES, 2000), comprovando que se encontram em uma situação mais profunda de vulnerabilidade.

Nas palavras de Soares (2000):

\begin{abstract}
A minha interpretação da discriminação contra negros é que existe uma visão do que seja o lugar do negro na sociedade, que é o de exercer um trabalho manual, sem fortes requisitos de qualificação em setores industriais pouco dinâmicos. Se o negro ficar no lugar a ele alocado, sofrerá pouca discriminação. Mas se porventura tentar ocupar um lugar ao sol, sentirá todo o peso das três etapas da discriminação sobre seus ombros. As mulheres negras arcam com todo o ônus da discriminação de cor e de gênero e ainda mais um pouco, sofrendo a discriminação setorial-regionalocupacional mais que os homens da mesma cor e as mulheres brancas (p.24-25).
\end{abstract}

Trazendo à baila o caso da explosão da fábrica de fogos de Santo Antônio de Jesus (BA), pode-se verificar que as trabalhadoras vítimas da tragédia estavam submersas nesse cruzamento de discriminação- pobres, negras e mulheres- razão pela qual, no próximo tópico analisar-se-á se a sentença proferida pela Corte IDH foi interseccional.

\title{
5. INTERSECCIONALIDADE E A SENTENÇA PROFERIDA PELA CORTE INTERAMERICANA DE DIREITOS HUMANOS
}

Antes de adentrar à análise da sentença proferida no presente caso, é necessário compreender a relevância da Corte IDH no cenário nacional e internacional e, para isso, será abordada brevemente a sua origem e o seu funcionamento dentro do Sistema Interamericano dos Direitos Humanos (SIDH).

O SIDH se divide em dois órgãos: a Comissão Interamericana de Direitos Humanos (CIDH) e a Corte Interamericana de Direitos Humanos (Corte IDH). A primeira tem como objetivo a promoção da observância dos direitos humanos, servindo como órgão consultivo na Organização dos Estados Americanos (OEA) e uma de suas competências consiste no recebimento de denúncias que versam sobre violações dos direitos humanos (PIOVESAN, 2013). Já a Corte IDH é um órgão jurisdicional, criado a partir da Convenção Americana de Direitos Humanos (1969), sua função se divide entre consultiva e contenciosa.

Como se pode observar no caso da explosão da fábrica de fogos, a Corte exerceu sua competência contenciosa. Salienta-se que para um Estado ser submetido ao julgamento da 
Corte é essencial reconhecer expressamente tal jurisdição ${ }^{4}$, conforme consta no art. 62 da Convenção Americana. Além disso, as sentenças proferidas pela Corte têm força jurídica vinculante e obrigatória, isto é, o Estado tem que cumprir a decisão, implementando-as no seu plano interno. O Estado não pode se omitir ou ser indiferente face ao julgamento, pois tal conduta poderá trazer sanções para este, como suspensão ou expulsão pela Assembleia Geral da OEA (PIOVESAN, 2013). Em outras palavras, os julgados proferidos pela Corte IDH têm um alto impacto não só na posição internacional do Estado-membro, como na jurisdição interna deste e a finalidade é proteger os direitos humanos, impedindo com que haja um retrocesso dentro do Estado de Direito.

Será objeto de análise o tópico B.3 do mérito da sentença, que dispõe a respeito da proibição de discriminação. A Corte IDH (2020) iniciou expondo que o princípio da igualdade e o da não discriminação são normas imperativas do direito internacional - jus cogens- e coordenam todo o ordenamento jurídico, assim sendo, os Estados não devem realizar condutas que causem discriminação de jure ou de facto.

No caso da explosão da fábrica de fogos, as violações neste tópico foram analisadas à luz dos artigos 1.1 - o qual versa sobre a garantia do livre e pleno exercício do direito de toda pessoa, sem discriminação- e art. 24- que dispõe sobre a igualdade de todos perante a leiambos da Convenção Americana de Direitos Humanos (1969), visto que a CIDH e os representantes do caso se direcionaram para as discriminações sofridas pelas vítimas, em razão de serem mulheres, afrodescendentes, estarem em condição de pobreza, assim como pela ausência de ações estatais positivas para garantir os direitos destas (CORTE IDH, 2020).

O entendimento da Corte em relação ao art. 1.1 da Convenção consiste em que tal norma tem um caráter geral e o conteúdo é estendido a todas as outras normas dispostas no tratado, sendo assim, aos Estados Partes devem respeitá-las, garantindo o pleno gozo dos direitos ali previstos. Caso haja o descumprimento, mediante qualquer tratamento discriminatório, o Estado deverá ser responsabilizado internacionalmente e, consequentemente "é por este motivo que existe um vínculo indissolúvel entre a obrigação de respeitar e garantir os direitos humanos e o princípio da igualdade e não discriminação" (CORTE IDH, 2020, p. 53).

\footnotetext{
${ }^{4}$ O Brasil reconheceu a jurisdição da Corte IDH no ano de 1998, por meio do Decreto $\mathrm{n}^{\circ} 4.463$, de 8 de novembro de 2002. Disponível em: http://www.planalto.gov.br/ccivil_03/decreto/2002/d4463.htm. Acesso em 20 ago. 2021.
} 
Quanto a discriminação em função da pobreza em que as trabalhadoras da fábrica estavam imersas, a Corte ressaltou que esta não é considerada uma categoria de proteção especial nos termos formais do art. 1.1 da Convenção, todavia, o rol deste artigo não é taxativo, mas sim enunciativo, portanto, não impede com que o Estado proíba esse tipo de discriminação no seu ordenamento interno. A pobreza, diante do seu caráter multidimensional, pode ser inserida dentro da categoria como a de posição econômica ou origem social ou outra condição social exposta no artigo supramencionado. Ademais, foi corroborado o entendimento de que cabe ao Estado tomar medidas que alterem o quadro discriminatório que persiste em sua sociedade, bem como impedir a discriminação por posição econômica (CORTE IDH, 2020).

Especificamente sobre o caso, asseverou a Corte (2020):

(...) as supostas vítimas eram pessoas que, em razão da discriminação estrutural por sua condição de pobreza, não podiam ter acesso a outra fonte de renda e tinham de se expor ao aceitar um trabalho em condições de vulnerabilidade, que contrastava com os mandatos da Convenção Americana, e que as expôs aos fatos que as vitimaram. Assim, o fato de que uma atividade econômica especialmente perigosa tenha se instalado na área está relacionado à pobreza e à marginalização da população que ali residia e reside. Para os moradores dos bairros de origem das trabalhadoras da fábrica de fogos, o trabalho que ali lhes ofereciam era a principal, senão a única opção de trabalho, pois se tratava de pessoas com muito baixo nível de escolaridade e alfabetização, que, ademais, eram rotulados como pouco confiáveis, e por essas razões não podiam ter acesso a outro emprego (p.54-55).

Para além da discriminação diante da condição de pobreza, a Corte considerou que houve a interseção de outros fatores de discriminação, o que fez com que a vulnerabilidade das vítimas aumentasse ainda mais. O entendimento da Corte foi de que as vítimas partilharam de fatores específicos de discriminação, sendo eles, a pobreza, o fato de serem mulheres e afrodescendentes, mais especificamente, algumas vítimas estavam grávidas ou eram meninas ou eram meninas e estavam grávidas. Em relação à gravidez, foi estabelecido pela Corte que esta situação configura uma condição de vulnerabilidade (CORTE IDH, 2020).

Quanto ao mérito, no que tange à discriminação contra a mulher, a Corte expôs pesquisas que ressaltavam que a desigualdade entre homens e mulheres no mercado de trabalho brasileiro era séria e que havia estereótipos marcados pelo gênero e pela raça que serviam de base para segregar mulheres afrodescendentes e indígenas em empregos subalternos. Além disso, houve a preocupação com os impactos que a pobreza causava sobre o grupo de mulheres socialmente excluídas ou marginalizadas, sobretudo, as mulheres 
brasileiras de ascendência africana. Outros dados foram trazidos em relação à população negra, que confirmaram que esta ainda é discriminada e a desigualdade que alcança as comunidades negras e mestiças causam efeitos negativos no exercício de outros direitos (CORTE IDH, 2020).

Diante disso, a Corte constatou que as vítimas da explosão da fábrica de fogos estavam envolvidas em padrões de discriminação tanto estrutural, quanto interseccional. A confluência de fatores como a pobreza estrutural, a maioria das mulheres e meninas ser afrodescendentes- dentre elas também tinham quatro grávidas- e a falta de opção de emprego fez com que aceitassem um trabalho perigoso e exploratório, assim como essa realidade permitiu com que uma fábrica sem condições mínimas de trabalho se mantivesse em funcionamento. Foi destacado também que perante essa situação das vítimas fazerem parte de um grupo vulnerável, os deveres do Estado para com elas eram maiores, no entanto, o Estado não adotou nenhuma garantia e aprofundou a experiência de vitimização delas (CORTE IDH, 2020).

No que diz respeito ao art. 24 da Convenção Americana, foi compreendido que este dispositivo garante tanto a igualdade material, quanto a igualdade substancial, sendo assim, o Estado tem a obrigação de adotar medidas que concretizem e efetivem os direitos dos grupos que são discriminados ou marginalizados. No caso em questão, o Estado estava ciente da vulnerabilidade das trabalhadoras vítimas, tendo em vista que existiam diversos dados divulgados pelos órgãos estatais sobre a situação econômica-social da população do município de Santo Antônio de Jesus (BA) e, ainda assim, não realizou as devidas fiscalizações, o que acentuou as discriminações sofridas pelas vítimas (CORTE IDH, 2020).

Por fim, a Corte (2020) concluiu:

(..) a situação de pobreza das supostas vítimas, associada aos fatores intersecionais de discriminação já mencionados, que agravavam sua condição de vulnerabilidade, (i) facilitou a instalação e o funcionamento de uma fábrica dedicada a uma atividade especialmente perigosa, sem fiscalização, seja dessa atividade perigosa, seja das condições de higiene e segurança no trabalho por parte do Estado; e (ii) levou as supostas vítimas a aceitar um trabalho que colocava em risco sua vida e sua integridade, bem como a de suas filhas e filhos menores de idade. Ademais, (iii) o Estado não adotou medidas destinadas a garantir a igualdade material no direito ao trabalho a respeito de um grupo de mulheres em situação de marginalização e discriminação. Essa situação implica que, no presente caso, não se garantiu o direito a condições de trabalho equitativas e satisfatórias, sem discriminação, nem tampouco o direito à igualdade, previstos nos artigos 24 e 26, em relação ao artigo 1.1 da Convenção (p.58). 
Na sentença, o Estado brasileiro foi condenado à pagar indenizações, bem como à implementar diversas medidas, dentre elas, as duas mais relevantes para o trabalho consistem em (i) elaborar e executar "um programa de desenvolvimento socioeconômico (...) com o objetivo de promover a inserção de trabalhadoras e trabalhadores dedicados à fabricação de fogos de artifício em outros mercados de trabalho (...)"' (CORTE IDH, 2020, p.88). Esse programa deverá ser realizado no prazo de dois anos, contados a partir da notificação da sentença, além disso, será necessário que o programa seja destinado à população de Santo Antônio de Jesus (BA), sobretudo, aos jovens maiores de 16 anos e às mulheres afrodescendentes, que se encontram em situação de pobreza. Deverá também incluir a criação de cursos de capacitação profissional e/ou técnicos que permitam a inserção em outras atividades no mercado de trabalho- tais como comércio, informática, agropecuária- visando a formação adequada aos trabalhadores (CORTE IDH, 2020).

A outra medida compreende em (ii) apresentar "um relatório sobre a aplicação das Diretrizes Nacionais sobre Empresas e Direitos Humanos" (CORTE IDH, 2020, p.88). O Estado deverá, no prazo de um ano, se empenhar em apresentar um relatório que demonstre que as empresas estão promovendo e apoiando as medidas de inclusão e não discriminação, por meio de programas que incentivem a contratação de grupos vulneráveis, bem como, implementando atividades voltadas para a educação em direitos humanos (CORTE IDH, 2020).

No mérito, a sentença da Corte constatou claramente as discriminações interseccionais que atingiram as vítimas da explosão da fábrica de fogos de Santo Antônio de Jesus (BA), sendo elas a pobreza, a raça, o gênero e até a gravidez, e asseverou diversas vezes o quanto a confluências desses fatores influenciaram na gravidade da situação, além disso, salientou que a condição das vítimas foi uma das bases para a fábrica "Vardo dos fogos" se manter com as condições degradantes de trabalho.

Em relação à condenação, a Corte novamente se mostrou atenta à imprescindibilidade de um programa de desenvolvimento que prestigie as mulheres afrodescendentes e à necessidade das empresas desenvolverem programas que insiram os grupos marginalizados, o que, objetivamente, sinaliza para a possibilidade concreta do desenvolvimento de entendimento jurisprudencial a respeito da relação interseccional que envolve pobreza, gênero, discriminação estrutural e necessidade do efetivo gozo dos direitos 
humanos em nosso país, em especial, nas regiões mais carentes de desenvolvimento socioeconômico.

\section{CONCLUSÃO}

Visto que o artigo se propôs a analisar se a sentença da Corte IDH foi de fato interseccional e para isto, ao longo do estudo, foram abordados o conceito da interseccionalidade, a exposição do caso da explosão da fábrica de fogos, o plano normativo brasileiro acerca do princípio da não discriminação, bem como a realidade da vulnerabilidade que atinge as mulheres negras no mercado de trabalho, conclui-se que a sentença foi interseccional, indo ao encontro do aporte teórico desenvolvido pela autora Kimberlé Crenshaw.

Foram considerados os cruzamentos das vias identitárias e a inseparabilidade dos fatores- pobreza, raça, gênero, gravidez- que confluíram e acometeram as trabalhadoras vítimas da tragédia. Todavia, no que tange à condenação, apesar de ter havido a recomendação para o desenvolvimento de um programa socioeconômico, que deve considerar os grupos marginalizados, a Corte poderia ter sido mais incisiva, podendo ter recomendado também um segundo programa mais específico para as mulheres que estão em situação vulnerabilidade, bem como ter salientado a importância da interseccionalidade na execução de todas as políticas públicas do Estado brasileiro.

De toda forma, ressalta-se a relevância do papel da Corte e a análise do entendimento que esta trouxe no mérito da sentença no caso dos empregados da fábrica de fogos de artifício de Santo Antônio de Jesus (BA), uma vez que reforça a indispensabilidade de uma leitura e aplicabilidade interseccional em termos dos direitos humanos, mormente naqueles casos em que urge o reconhecimento e a salvaguarda desses direitos, pois se trata de grupos em situação inequívoca de vulnerabilidade decorrente da discriminação estrutural calcada na pobreza e nas opressões ou desigualdades interseccionais.

\section{REFERÊNCIAS}

AKOTIRENE, Carla. O que é interseccionalidade?. São Paulo: Ed. Sueli Carneiro; Editora Jandaíra, 2020. 
ATLAS DO DESENVOLVIMENTO HUMANO NO BRASIL. Vulnerabilidade no município - Santo Antônio de Jesus/BA - 2000 e 2010, 2017. Disponível em: http://www.atlasbrasil.org.br/perfil/municipio/292870\#secvulnerabilidade. Acesso em: 09 ago. 2021.

BRASIL. Decreto $\mathbf{n}^{0}$ 65.810, de 8 de dezembro de 1969. Promulga a Convenção Internacional sobre a Eliminação de todas as Formas de Discriminação Racial. Disponível em: http://www.planalto.gov.br/ccivil_03/decreto/1950-1969/D65810.html. Acesso em: 02 set. 2021.

BRASIL. Constituição da República Federativa do Brasil. 1988. Disponível em: http://www.planalto.gov.br/ccivil_03/constituicao/constituicaocompilado.htm. Acesso em: 22 ago. 2021.

BRASIL. Decreto $n^{0}$ 4.377, de 13 de setembro de 2002. Promulga a Convenção sobre a Eliminação de Todas as Formas de Discriminação contra a Mulher, de 1979. Disponível em: http://www.planalto.gov.br/ccivil_03/decreto/2002/d4377.htm. Acesso em: 02 set. 2021.

BRASIL. Decreto $\mathbf{n}^{\mathbf{0}} \mathbf{1 0 . 0 8 8}$, de 5 de novembro de 2019. Consolida atos normativos editados pelo Poder Executivo Federal que dispõem sobre a promulgação de convenções e recomendações da Organização Internacional do Trabalho - OIT ratificadas pela República Federativa do Brasil. Disponível em: https://www.planalto.gov.br/ccivil_03/_ato20192022/2019/decreto/d10088.htm. Acesso em: 02 set. 2021.

CHO, Sumi; CRENSHAW, Kimberlé Williams; MCCALL, Leslie. Toward a Field of Intersectionality Studies: Theory, Applications, and Praxis. Signs: Journal of Women in Culture and Society, Chicago, v. 38, n. 4, p. 785-810, 2013. DOI: 10.1086/669608.

COMISSÃO INTERAMERICANA DE DIREITOS HUMANOS. Informe $\mathbf{N}^{\mathbf{0}} \mathbf{. 2 5 / 1 8}$, Caso 12.428. Admissibilidade e Mérito. Empregados da Fábrica de Fogos de Santo Antônio de Jesus e seus familiares. Brasil. 2 de março de 2018.

COMITÊ SOBRE DIREITOS ECONÔMICOS, SOCIAIS E CULTURAIS DAS NAÇÕES UNIDAS. Comentário Geral $n^{0} 16$ - Article 3: the equal right of men and women to the enjoyment of all economic, social and cultural rights. Genebra, 2005. Disponível em: https://www.escr-net.org/resources/general-comment-n-16-article-3-equal-right-men-andwomen-enjoyment-all-economic-social-and. Acesso em: 02 set. 2021.

CONVENÇÃO AMERICANA SOBRE OS DIREITOS HUMANOS. 1969. Disponível em: https://www.cidh.oas.org/basicos/portugues/c.convencao_americana.htm. Acesso em: 09 set. 2021.

CORTE INTERAMERICANA DE DIREITOS HUMANOS. Sentença Corte Interamericana - Caso Empregados da Fábrica de Fogos de Santo Antônio de Jesus e seus familiares vs. Brasil. 2020. Disponível em: http://www.global.org.br/wpcontent/uploads/2020/10/Sentencia_Fabrica_de_Fogos.pdf. Acesso em: 14 ago.2021. 
CRENSHAW, Kimberlé. Demarginalizing the Intersection of Race and Sex: A Black Feminist Critique of Antidiscrimination Doctrine, Feminist Theory, and Antiracist Politics. University of Chicago Legal Forum, p. 538-554, 1989.

CRENSHAW, Kimberlé. Documento para o encontro de especialistas em aspectos da discriminação racial relativos ao gênero. Revista Estudos Feministas, Florianópolis, v. 10, n. 1, p. 171-188, 2002. http://dx.doi.org/10.1590/s0104-026x2002000100011.

CRENSHAW, Kimberlé. A interseccionalidade na discriminação de raça e gênero. Painel: Cruzamentos de raça e gênero. Ação Educativa, 2012.

ESTATÍSTICAS SOCIAIS. Diferença cai em sete anos, mas mulheres ainda ganham 20,5\% menos que homens. Censo 2022. 08 mar. 2019. Disponível em: https://censo2022.ibge.gov.br/2012-agencia-de-noticias/noticias/23924-diferenca-cai-em-seteanos-mas-mulheres-ainda-ganham-20-5-menos-que-homens.html. Acesso em: 24 ago. 2021

FREDMAN, Sandra. Engendering Socio-Economic Rights. Oxford Legal Studies Research Paper, Oxford, n. 54, 2010.

GOMES, Laurentino. Escravidão. Volume I. Do primeiro leilão de cativos em Portugal até a morte de Zumbi dos Palmares. São Paulo: Globo Livros, $1^{\text {a }}$ Ed., 2019.

HIRATA, Helena. Gênero, classe e raça Interseccionalidade e consubstancialidade das relações sociais. Tempo Social, São Paulo, v. 26, n. 1, p. 61-73, 2014. DOI: 10.1590/S010320702014000100005. Disponível em: https://www.revistas.usp.br/ts/article/view/84979. Acesso em: 02 set. 2021.

IPEA. INSTITUTO DE PESQUISA ECONÔMICA APLICADA. Retrato das Desigualdades de Gênero e Raça- 1995 a 2015. Brasília, 2017. Disponível em: \&lt;https://www.ipea.gov.br/portal/images/stories/PDFs/170306_retrato_das_desigualdades_d e_genero_raca.pdf\&gt;. Acesso em: 26 ago. 2021.

KAPUR, Ratna. Revisioning the Role of Law in Women's Human Rights Struggles. In: Meckled-García, Saladin e Çali, Basak (org.), The Legalization of Human Rights: Multidisciplinary Perspectives on Human Rights and Human Rights Law. New York: Routledge, p. 101-116, 2006.

PIOVESAN, Flávia. Direitos Humanos e o Direito Constitucional Internacional. $14^{\mathrm{a}}$ ed. São Paulo: Saraiva, 2013.

SOARES, Sergei Suarez Dillon. O perfil da discriminação no mercado de trabalho homens negros, mulheres brancas e mulheres negras. Brasília: Ipea, 2000. Disponível em: https://www.ipea.gov.br/portal/index.php?option=com_content\&view=article\&id=4020:td0769-perfil-da-discriminacao-no-mercado-de-trabalho-homens-negros-mulheres-brancas-emulheres-negras\&catid=314:2000\&directory=1. Acesso em: 22 ago. 2021. 
TARDÁGUILA, Cristina. Maior produtor de fogos de artifícios do país, o município em MG convive com explosões e "exército" de feridos: Com 72 fábricas, Santo Antônio do Monte registrou oito acidentes com 14 mortos em menos de três anos. O Globo. Rio de Janeiro. 05 jul.2015. Disponível em: https://oglobo.globo.com/politica/maior-produtor-defogos-de-artificios-do-pais-municipio-em-mg-convive-com-explosoes-exercito-de-feridos16667079. Acesso em: 24 ago.2021.

TOMASONI, Sônia Marise Rodrigues Pereira. Dinâmica socioespacial da produção de fogos de artifícios em Santo Antônio de Jesus- BA: território fogueteiro. 2015. $167 \mathrm{f}$. Tese (Doutorado em Geografia) - Universidade Federal de Sergipe, São Cristóvão, 2015. Disponível em:https://ri.ufs.br/bitstream/riufs/5453/1/SONIA_MARISE_RODRIGUES_PEREIRA_TO MASONI.pdf. Acesso em: 15 ago. 2021. 